\title{
Zerumbone inhibits melanoma cell proliferation and migration by altering mitochondrial functions
}

\author{
HUA YAN ${ }^{1}$, MING-YUAN REN ${ }^{2}$, ZHENG-XIANG WANG ${ }^{1}$, SHI-JUN FENG ${ }^{1}$, SI LI $^{2}$, \\ YI CHENG ${ }^{2}$, CAI-XIA HU ${ }^{2}$, SHUN-QIANG GAO ${ }^{2}$ and GUO-QIANG ZHANG ${ }^{2}$ \\ ${ }^{1}$ Department of Dermatology, The Center Hospital of Cangzhou, Cangzhou, Hebei 061001; \\ ${ }^{2}$ Department of Dermatology, Fourth Hospital, Hebei Medical University, Shijiazhuang, Hebei 050011, P.R. China
}

Received January 23, 2016; Accepted December 1, 2016

DOI: $10.3892 / \mathrm{ol} .2017 .5742$

\begin{abstract}
It has been reported that zerumbone (ZER) has marked effects on the regulation of cell proliferation and migration in multiple types of cancer, and has anti-cancer effects on various types of malignant cell. However, the effects and underlying molecular mechanisms of treatment with ZER on melanoma cells remain unclear. In the present study, the effect of treatment with ZER on the proliferation, migration and mitochondrial function of the human melanoma cell line CHL-1 was investigated. The results of the present study indicated that treatment with ZER significantly inhibited CHL-1 cell proliferation $(\mathrm{P}<0.001)$. Cell migration analysis further demonstrated that ZER inhibited the migration of CHL-1 cells $(\mathrm{P}<0.001)$. Treatment with ZER significantly increased cellular reactive oxygen species levels $(\mathrm{P}<0.001)$, reduced matrix membrane potential $(\mathrm{P}<0.001)$, decreased ATP $(\mathrm{P}<0.001)$ and mitochondrial DNA $(\mathrm{P}<0.001)$ levels, and decreased mitochondrial transcription factor A mRNA levels $(\mathrm{P}=0.002)$. The results of the present study suggested that the inhibition of proliferation and migration was mediated by altered mitochondrial function. In conclusion, the results of the present study suggested that ZER has chemotherapeutic effects on human melanoma cells by altering mitochondrial function.
\end{abstract}

\section{Introduction}

Melanoma is one of the most aggressive and lethal types of malignant tumor, and is characterized by inconspicuous onset and high malignancy $(1,2)$. Annually, there are 160,000 cases of melanoma and 48,000 cases of melanoma-associated mortality worldwide (3). Treatments for human melanoma

Correspondence to: Professor Guo-Qiang Zhang, Department of Dermatology, Fourth Hospital, Hebei Medical University, 12 Jian-Kang Road, Shijiazhuang, Hebei 050011, P.R. China E-mail: zlx090702@163.com

Key words: melanoma, zerumbone, cell proliferation, cell migration, mitochondrial function include surgery and immunotherapy; however, these do not lead to efficient results (3). Despite recent advances in therapeutic strategies, melanoma with distant metastasis maintains a poor prognosis and a total 5-year survival rate of $16 \%$ (4). Therefore, investigation into effective therapeutic agents with novel mechanisms of action is required.

Zerumbone (ZER), or 2,6,9,9-tetramethylcycloundeca-2,6,10-trien-1-one, is a monocyclic sesquiterpene derived from the tropical ginger plant Zingiber zerumbet, which has been used in traditional Chinese medicine to treat cancer, fever and other types of disease (5). The structure of ZER is visualized in Fig. 1. The biological activities of ZER, including anticancer and antitumor effects, have previously been exploited (6,7). Previous studies have reported that the anticancer effects of ZER involve distinct signaling pathways in various types of cell line (8). The cytotoxic effect of treatment with ZER on leukemia cells was observed to be induced by cell cycle arrest, and tumor necrosis factor receptor superfamily member 6 (Fas)- and mitochondria-mediated apoptosis (9). Treatment with ZER inhibited human colonic adenocarcinoma cell proliferation in association with mitochondrial transmembrane dysfunction, which led to apoptosis (10). Treatment of a wild-type rat liver cell line with ZER resulted in a significant induction of glutathione S-transferase, whereas this effect was not observed with its reduced analogues (11). Treatment of cancer cells with ZER was demonstrated to lead to the inhibition of sonic hedgehog protein/zinc finger protein GLI-mediated transcription, downregulation of CXC chemokine receptor type 4 , and inhibition of stromal cell-derived factor 1-induced breast and pancreatic cancer invasion $(12,13)$. As ZER has been previously used as an anticancer drug without significant toxic side effects, it is a potential treatment of melanoma. It was reported that ZER was able to suppress skin tumor initiation (14). However, the effects of treatment with ZER on melanoma, and the associated underlying molecular mechanisms, remain to be elucidated.

Therefore, the aim of the present study was to investigate whether treatment with ZER was able to efficiently inhibit melanoma cell proliferation and migration. A CHL-1 melanoma cell line model was treated with varying concentrations of ZER. Furthermore, it was observed that the effects of treatment with ZER were mediated through the regulation of mitochondrial function, including reactive oxygen species 
(ROS), ATP and mitochondrial DNA (mtDNA) levels, and mitochondrial matrix potential (MMP).

\section{Materials and methods}

Cell culture and reagents. The human skin melanoma cell line CHL-1 used in the present study was purchased from the American Type Culture Collection (Manassas, VA, USA). ZER, dimethyl sulfoxide (DMSO) and Hoechst ${ }^{\circledR} 33342$ were purchased from Sigma-Aldrich (Merck Millipore, Darmstadt, Germany). The Cell Counting Kit-8 (CCK-8) was purchased from Dojindo Molecular Technologies, Inc. (Kumamoto, Japan) and the fetal bovine serum (FBS) was purchased from Hyclone (GE Healthcare Life Sciences, Logan, UT, USA). The CHL-1 cells were grown in Dulbecco's modified Eagle's medium (DMEM; Gibco; Thermo Fisher Scientific, Inc., Waltham, MA, USA) supplemented with $10 \%$ FBS and $1 \%$ penicillin-streptomycin, and incubated at $37^{\circ} \mathrm{C}$ in a humidified atmosphere containing $5 \% \mathrm{CO}_{2}$. The culture medium was replaced between 2 and 3 times/week.

Cell viability and proliferation assays. Melanoma tumor cell viability was evaluated using the CCK- 8 assay. CHL- 1 cells were seeded in 96-well plates at a density of $1 \times 10^{5}$ cells/well and allowed to adhere for $24 \mathrm{~h}$. Then culture media was removed and cells were treated with $0,1,2,4,8$ and $16 \mu \mathrm{g} / \mathrm{ml}$ ZER dissolved in DMSO for $48 \mathrm{~h}$. Control cultures were treated with $0.1 \%$ DMSO. Subsequently, $10 \mu 1$ CCK- 8 was added to each well and the plates were incubated at $37^{\circ} \mathrm{C}$ for $2 \mathrm{~h}$. Optical density (OD) was measured at a wavelength of $450 \mathrm{~nm}$ using a multimode plate reader (Tecan Group, Ltd., Zürich, Switzerland). Values are represented as the fold change in OD value compared with the control cells. Cell proliferation assays were also performed by detecting 5-bromo-20-deoxyuridine (BrdU)-labeled DNA using an anti-BrdU monoclonal antibody conjugated to peroxidase (Cell Proliferation ELISA; Roche Applied Science, Penzberg, Germany). The amount of BrdU-labeled DNA was quantified using the ELISA, according to the manufacturer's protocol.

Cell migration assay. Cell migration was assessed using a Transwell migration assay. A total of $1 \times 10^{5}$ cells in $200 \mu \mathrm{l}$ serum-free media were seeded into the upper chamber of Transwell ${ }^{\circledR}$ plates (BD Biosciences, Franklin Lakes, NJ, USA) and $200 \mu \mathrm{l}$ DMEM containing $10 \%$ FBS was added to the lower chamber. Following treatment with ZER for $48 \mathrm{~h}$ at $37^{\circ} \mathrm{C}$ in $5 \% \mathrm{CO}_{2}$, the non-invasive cells in the upper chamber were removed. The invasive cells in the lower chamber were stained with Hoechst 33342 for 10 min, imaged and counted using an upright fluorescence microscope (Olympus Corporation, Tokyo, Japan).

Intracellular ROS assay. Intracellular ROS production was determined using the 2',7'-dichlorofluorescin-diacetate (DCFH-DA) oxidation kit (Beyotime Institute of Biotechnology, Haimen, China), according to the manufacturer's protocol. A total of $1 \times 10^{5}$ cells/well were seeded in 96-well plates and following treatment with ZER, were incubated with DCFH-DA at $37^{\circ} \mathrm{C}$ for $20 \mathrm{~min}$. DCFH-DA passively diffused into the cells and was deacetylated by esterases to form $\mathrm{DCFH}$,

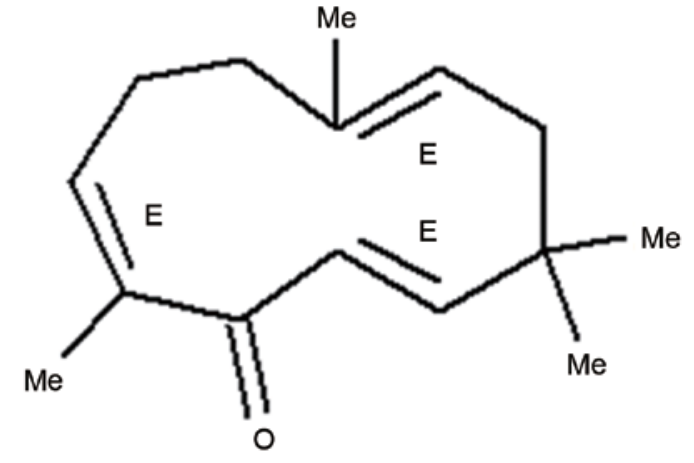

Figure 1. Chemical structure of zerumbone.

which reacted with any ROS present to form the fluorescent product DCF within the cells (15). The fluorescence was read at a wavelength of $485 \mathrm{~nm}$ (excitation) and $530 \mathrm{~nm}$ (emission) using a monochromator microplate reader (Tecan Group, Ltd.).

Measurement of MMP. the JC-1 kit (Beyotime Institute of Biotechnology) was used to measure the MMP of CHL-1 cells, according to the manufacturer's protocol. Following treatment with ZER, $1 \times 10^{5}$ cells were cultured in 24 -well plates and incubated with $5 \mu \mathrm{g} / \mathrm{ml} \mathrm{JC}-1$ staining solution for $20 \mathrm{~min}$ at $37^{\circ} \mathrm{C}$. Cells were subsequently rinsed twice with JC-1 staining buffer, and the fluorescence intensities of mitochondrial JC-1 monomers $\left(\lambda_{\text {excitation }}, 514 \mathrm{~nm} ; \lambda_{\text {emission }}, 529 \mathrm{~nm}\right)$ and aggregates $\left(\lambda_{\text {excitation }}, 585 \mathrm{~nm} ; \lambda_{\text {emission }}, 590 \mathrm{~nm}\right)$ were detected using a monochromator microplate reader. The MMP of CHL-1 cells in each treatment group was calculated as the red/green fluorescence ratio.

Evaluation of cellular ATP levels. Cellular ATP levels were measured using a firefly luciferase-based ATP assay kit (Beyotime Institute of Biotechnology), according to the manufacturer's instructions. Following treatment with ZER for $48 \mathrm{~h}$, cells were centrifuged at $12,000 \times \mathrm{g}$ for $5 \mathrm{~min}$ at $4^{\circ} \mathrm{C}$. In 24-well plates, $100 \mu 1$ supernatant was mixed with $100 \mu \mathrm{l}$ ATP detection solution (working dilution) that was part of the kit. Luminescence was measured using a monochromator microplate reader.

Evaluation of $m t D N A$ levels. The quantitative polymerase chain reaction (qPCR) was used to evaluate mtDNA levels as previously described (16-18). A total of $1 \times 10^{6}$ cells/well were seeded into six-well plates. Following treatment with ZER, total cellular DNA was extracted using the E.Z.N.A. ${ }^{\circledR}$ Tissue DNA kit (Omega Bio-Tek, Inc., Norcross, GA, USA), according to the manufacturer's protocol. As previously described, relative amounts of mtDNA were compared with nuclear DNA copy numbers. The mtDNA amplicons were generated from two distinct segments of the mtDNA genes: Mitochondrially encoded cytochrome $c$ oxidase I (COX1), encoded for on the heavy strand of mtDNA; and mitochondrially encoded NADH:ubiquinone oxidoreductase core subunit 6 (ND6), encoded for on the light strand of mtDNA. The nuclear amplicon was generated by amplification a segment of the $\beta$-actin gene, which was selected as the internal control. The following mtDNA primers were used: COX1 forward, 5'-CCA 
A

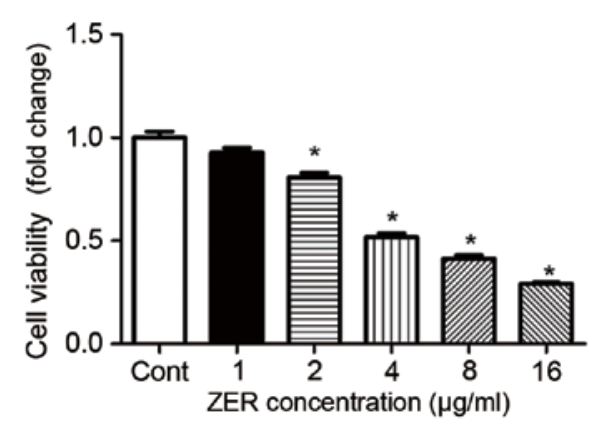

B

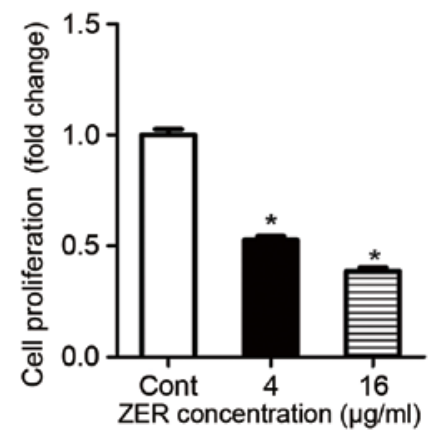

Figure 2. Treatment with ZER decreases human CHL-1 melanoma cell viability and proliferation. Melanoma cell lines were treated with $0,1,2,4,8$ and $16 \mu \mathrm{g} / \mathrm{ml} \mathrm{ZER}$, prior to the determination of (A) cell viability and (B) proliferation, relative to the Cont cells. Values are presented as the mean \pm standard error of the mean $(\mathrm{n}=8)$. ${ }^{*} \mathrm{P}<0.05$ vs. Cont. ZER, zerumbone; Cont, control.

CTTCGCCATCATATTCGTAGG-3' and reverse, 5'-TCTGAG TAGCGTCGTGGTATTCC-3' (fragment length, $90 \mathrm{bp}$ ); and ND6 forward, 5'-TCACCCAGCTACCACCATCATTC-3' and reverse, 5'-CACTGAGGAGTACCCAGAGACTTG-3' (fragment length, $250 \mathrm{bp}$ ). The primers for $\beta$-actin were: Forward, 5'-CCACACCCGCCACCAGTTC-3' and reverse, 5'-CCTTCT GACCCATTCCCACCATC-3' (fragment length, 173 bp). The qPCR was performed using the Real Time PCR Detection System (Bio-Rad Laboratories, Inc., Hercules, CA, USA) and the SYBR-Green I detection method, according to the manufacturer's protocol.

Reverse transcription-quantitative polymerase chain reaction $(R T-q P C R)$. Total RNA was isolated from cortical neurons using TRIzol reagent (Invitrogen; Thermo Fisher Scientific, Inc.). The first-strand cDNA was generated from total RNA $(1 \mu \mathrm{g})$ using a High-Capacity cDNA Reverse Transcription kit (Invitrogen; Thermo Fisher Scientific, Inc.). Following equalization of the RNA quantity in each group, the mRNA levels were quantitated using a Bio-Rad iQ5 Gradient Real-Time PCR system (Bio-Rad Laboratories, Inc.), and GAPDH was used as an endogenous control. Primers used for all RT-qPCR experiments were as follows: TFAM forward 5'-GGTGTATGAAGCGGATTT-3' and reverse, 5'-CTT TCTTCTTTAGGCGTTT-3'; GAPDH forward 5'-AAGGTG AAGGTCGGAGTCAA-3' and reverse 5'-AATGAAGGG GTCATTGATGG-3'. qPCR was performed using the Real Time PCR Detection System (Bio-Rad Laboratories, Inc.) and the SYBR-Green I (Applied Biosystems; Thermo Fisher Scientific, Inc.) detection method, according to the manufacturer's protocol. The PCR system contained the following: 2.5 $\mu 1$ 10X PCR buffer, $1.5 \mu 1 \mathrm{MgCl}_{2}$ solution, $0.5 \mu \mathrm{l}$ forward primer, $0.5 \mu \mathrm{l}$ reverse primer, $2.5 \mu \mathrm{l}$ Taq polymerase and $1 \mu \mathrm{l}$ cDNA. Thermocycling conditions for qPCR were as follows: $95^{\circ} \mathrm{C}$ for $15 \mathrm{~min}$, followed by 40 cycles of $95^{\circ} \mathrm{C}$ for $30 \mathrm{sec}$, $60^{\circ} \mathrm{C}$ for $20 \mathrm{sec}$ and $72^{\circ} \mathrm{C}$ for $30 \mathrm{sec}$. RT-qPCR products were detected using $1.5 \%$ agarose gel electrophoresis and quantified using the $2^{-\Delta \Delta \mathrm{Cq}}$ method (19).

Statistical analysis. Values are presented as the mean \pm standard error of the mean for triplicate experiments. Statistical analysis was performed using SPSS version 16.0 (SPSS, Inc.,
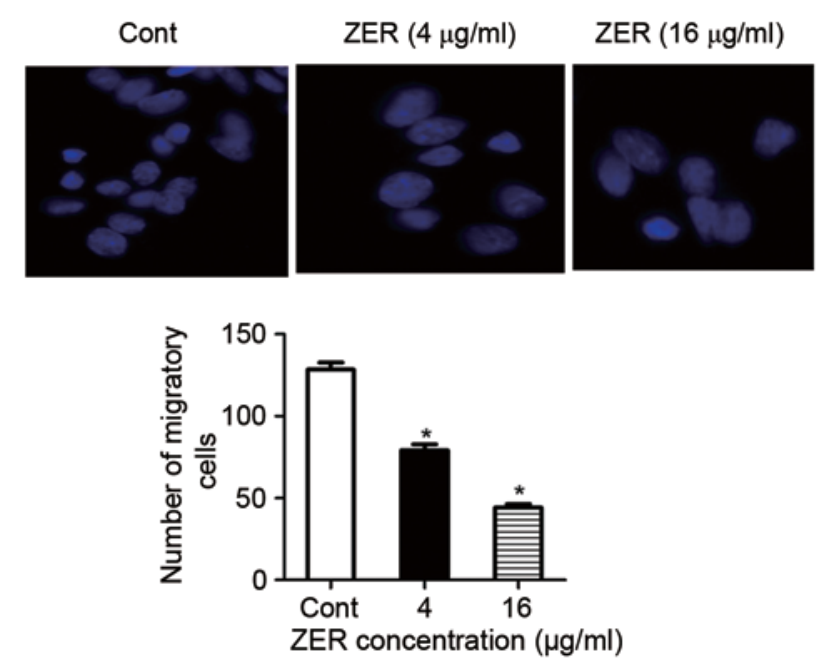

Figure 3. Treatment with ZER increases CHL-1 cell migration. Values are presented as the mean \pm standard error of the mean. ${ }^{*} \mathrm{P}<0.05$ vs. Cont. ZER, zerumbone; Cont, control.

Chicago, IL, USA). Data were statistically analyzed using the one-way analysis of variance or Student's $t$ test. $\mathrm{P}<0.05$ was considered to indicate a statistically significant difference.

\section{Results}

Chemotherapeutic effect of treatment with ZER in human CHL-1 melanoma cells. The chemotherapeutic effect of treatment with ZER in human melanoma cells was investigated. Following treatment with $2-16 \mu \mathrm{g} / \mathrm{ml} \mathrm{ZER,} \mathrm{CHL-1} \mathrm{cell} \mathrm{viability}$ was significantly decreased in a dose-dependent manner compared with the control cells $(\mathrm{F}=199.12$; $\mathrm{P}<0.001$; Fig. 2A). Consistently, the results of the BrdU assay demonstrated significantly decreased cell proliferation following treatment with ZER compared with the control cells ( $\mathrm{F}=258.38$; $\mathrm{P}<0.001$; Fig. 2B). Furthermore, the effect of treatment with ZER on CHL-1 cell migration was determined. Results of the Transwell migration assay indicated that treatment with ZER significantly inhibited CHL-1 cell migration compared with the untreated cells in a dose-dependent manner $(F=152.22$; $\mathrm{P}<0.001$; Fig. 3). 

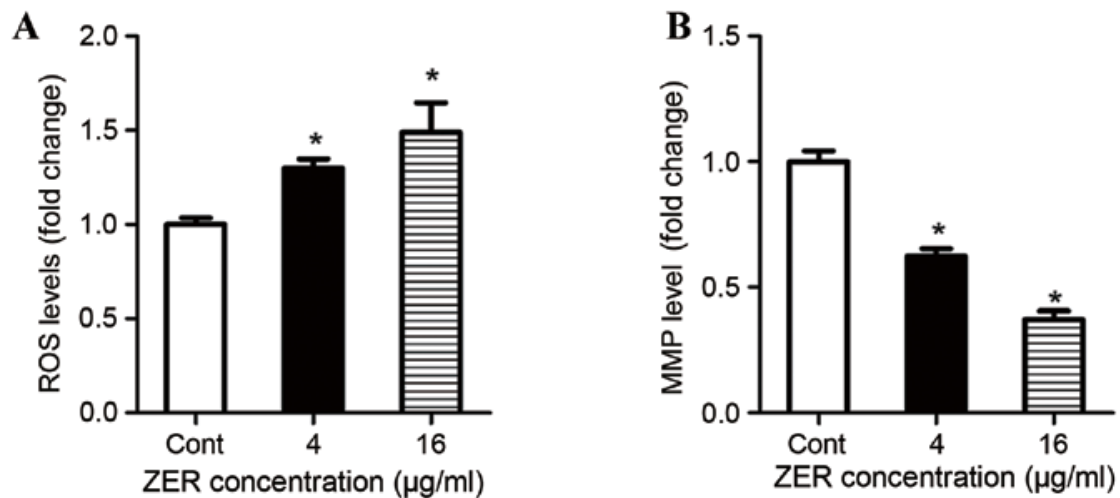

Figure 4. Treatment with ZER decreases ROS production and the MMP in CHL-1 cells. CHL-1 cells were treated with 4 and $16 \mu \mathrm{g} / \mathrm{ml}$ ZER for $48 \mathrm{~h}$. (A) The levels of ROS production were assessed and cellular fluorescence intensity values are presented relative to the Cont cells. (B) The MMP of the CHL-1 cells was determined using a JC-1 kit, relative to the Cont cells. Values are presented as the mean \pm standard error of the mean $(n=5)$. "P<0.05 vs. Cont. ZER, zerumbone; ROS, reactive oxygen species; MMP, mitochondrial matrix potential; Cont, control.

A

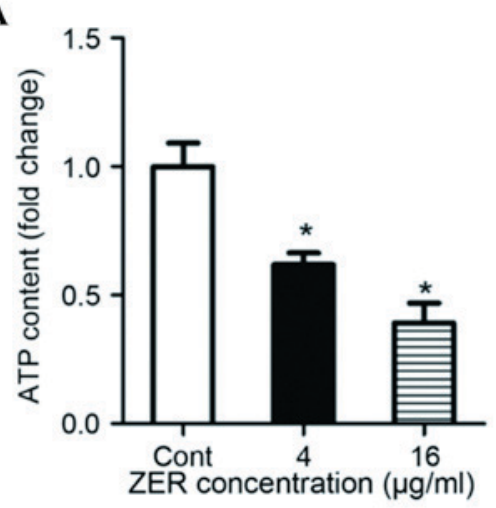

B

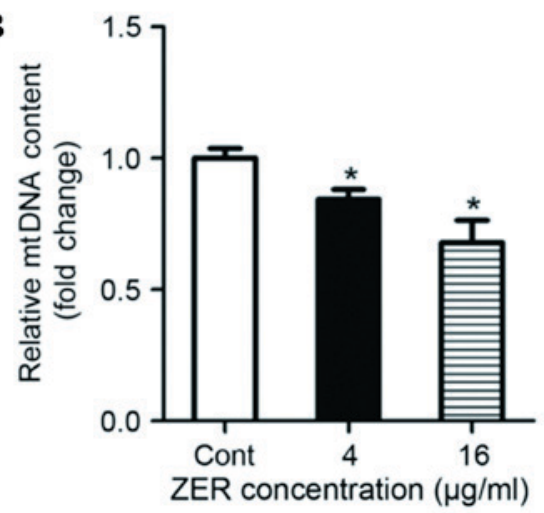

Figure 5. Treatment with ZER affects mitochondrial biogenesis. (A) Mitochondrial ATP generation decreased following treatment with ZER, relative to the Cont cells. (B) mtDNA levels decreased following treatment with ZER, relative to the Cont cells. Values are presented as the mean \pm standard error of the mean. ${ }^{*} \mathrm{P}<0.05$ vs. Cont. ZER, zerumbone; Cont, control; mtDNA, mitochondrial DNA.

Treatment with ZER promotes intracellular ROS generation and reduces the MMP. It is well-documented that the induction of cell death by certain antitumor agents is associated with ROS generation and the perturbation of mitochondrial function $(20,21)$. To understand the underlying mechanism of inhibited cell proliferation and migration, ROS generation and the MMP were investigated in CHL-1 cells following treatment with ZER. Following treatment with ZER, ROS production was significantly increased in CHL-1 cells compared with the control cells in a dose-dependent manner ( $\mathrm{F}=23.96$; $\mathrm{P}<0.001$; Fig. 4A). Furthermore, following treatment with ZER, the MMP of CHL-1 cells was significantlydecreased compared with the control cells ( $\mathrm{F}=99.37$; $\mathrm{P}<0.001$; Fig. 4B).

Treatment with ZER decreases mitochondrial biogenesis. To determine whether ZER affects mitochondrial biogenesis, cells were treated with ZER for $48 \mathrm{~h}$. Mitochondrial ATP synthesis was measured, and the results demonstrated that treatment with ZER significantly decreased ATP content compared with the untreated cells $(\mathrm{F}=25.13 ; \mathrm{P}<0.001 ;$ Fig. 5A). The level of mtDNA was also decreased following treatment with ZER compared with the untreated cells $(\mathrm{F}=19.52 ; \mathrm{P}<0.001 ;$ Fig. 5B).

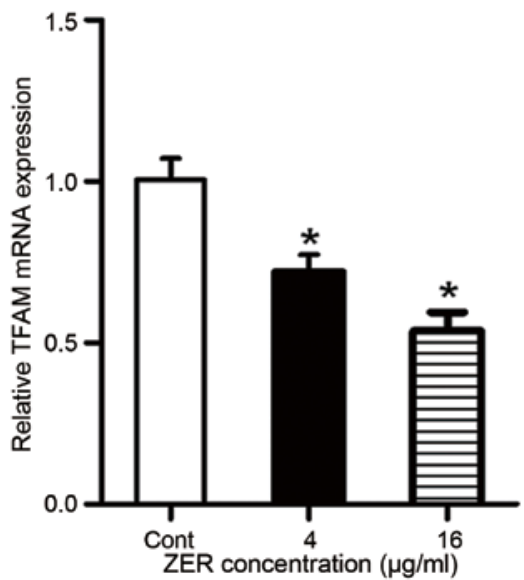

Figure 6. Treatment with ZER decreases TFAM mRNA expression in CHL-1 cells, relative to the Cont cells. TFAM mRNA expression was normalized to GAPDH mRNA expression. Data are presented as the mean \pm standard error of the mean. ${ }^{*} \mathrm{P}<0.05$ vs. Cont. ZER, zerumbone; TFAM, mitochondrial transcription factor A; Cont, control.

In addition, mRNA expression of mitochondrial transcription factor A (TFAM), a mitochondrial biogenesis factor, was 
evaluated using RT-qPCR (Fig. 6). The results demonstrated that treatment with 4 and $16 \mu \mathrm{g} / \mathrm{ml}$ ZER significantly decreased TFAM mRNA expression compared with the untreated cells ( $\mathrm{F}=19.48 ; \mathrm{P}=0.002$; Fig. 6). These results suggest that $\mathrm{ZER}$ inhibits mitochondrial biogenesis.

\section{Discussion}

In the present study, treatment with ZER was demonstrated to suppress proliferation and migration of the melanoma cell line CHL-1. Furthermore, the results of the present study presented a novel mechanism of ZER action whereby mitochondrial activity is decreased; leading to a subsequent increase in ROS generation, decrease in MMP, and reduction in ATP and mtDNA levels.

Melanoma is the most lethal form of skin cancer. Although significant progress has been made in melanoma detection and treatment, 5-year survival rates of patients with stage IV melanoma are $<5 \%(22,23)$. Therefore, there is a requirement to investigate the potential of novel agents and develop more effective anticancer therapies. The use of natural anticancer agents is regarded to be pharmaceutically safe due to their minimal cytotoxicity (24). Zerumbone is one such compound, which is well-tolerated and does not cause weight loss or other side effects (14). Zerumbone induces apoptosis in chronic myelogenous leukemia cells through increased calcium levels, generation of ROS and upregulation of soluble histone H2AX (25). The cytotoxic effect of ZER on leukemia cells was observed to be mediated through cell cycle arrest and Fas- and mitochondria-mediated apoptosis (9). ZER has been demonstrated to inhibit the proliferation of human colonic adenocarcinoma cell lines in association with mitochondrial transmembrane dysfunction, which led to apoptotic cell death (10). In addition, ZER has been demonstrated to cause $\mathrm{G}_{2} / \mathrm{M}$ phase cell cycle arrest and apoptosis regulator BAX/apoptosis regulator BAK-mediated apoptosis in human breast cancer cells (14). Although the cytotoxic actions of ZER have previously been observed in cancer cells in vivo and in vitro $(5,26)$, to the best of our knowledge the inhibitory effects of ZER on CHL-1 cells remains to be elucidated. In the present study, an in vitro model demonstrated that treatment with ZER inhibits CHL-1 cell proliferation in a dose-dependent manner when measured using the BrdU assay. Furthermore, the effect of treatment with ZER on migration was evaluated using a Transwell migration assay. These results demonstrated that ZER inhibited CHL-1 cell migration. The results of the present study indicate that treatment with ZER inhibits proliferation and migration in melanoma cells.

The incidence of metastatic melanoma has increased over the previous three decades and the mortality rate is increasing more rapidly compared with other types of cancer $(27,28)$. Tumor cell migration is a critical step in tumor metastasis and the inhibition of migration is a practical approach to antitumor treatment (29). As tumor metastasis is the primary cause of cancer-associated mortality and energy metabolism is essential to tumor metastasis, the effect of treatment with ZER on mitochondrial bioenergetics was evaluated. The mitochondrion, as the primary form of cellular energy generation, serves an important role in migration $(30,31)$. Mitochondria are the primary generators of ATP through oxidative phosphorylation and mitochondria-mediated apoptosis occurs in response to a range of stimuli. Mitochondria are also the primary source of ROS production and damaged mitochondria are able to release increased levels of ROS (32). ROS are able to cause MMP disruption through activation of mitochondrial permeability transition, which inhibits cell migration $(33,34)$. MMP is a result of the asymmetric distribution of protons and other ions across the inner membrane of the mitochondrion, and is necessary for sustaining the functions of the mitochondrion. MMP is one of the most reliable indicators of mitochondrion permeability $(35,36)$. Mitochondrial biogenesis has been observed to be useful in attenuating any detrimental consequence on mitochondrial function (37). In the present study, the MMP, and ROS, ATP and mtDNA levels, were evaluated in human melanoma CHL-1 cells following treatment with ZER. The results of the present study demonstrated that treatment with ZER significantly increased the cellular level of ROS and reduced the MMP. In addition, treatment with ZER significantly decreased melanoma cell mitochondrial bioenergetics, including mtDNA and mitochondrial ATP levels.

In conclusion, the results of the present study demonstrate that treatment with ZER has antiproliferative and antimigratory effects in human melanoma cells in vitro, through the downregulation of mitochondrial function. The present study indicates that ZER is a potentially effective drug for the management of melanoma.

\section{References}

1. Siegel R, Ma J, Zou Z and Jemal A: Cancer statistics, 2014. CA Cancer J Clin 64: 9-29, 2014.

2. Zhou L, Lu Y, Yang G and Wu J: Research on tumorigenicity of cinnamaldehyde in melanoma cell lines and its mechanism. Tumour Biol 35: 5717-5722, 2014.

3. Gibot L, Chabaud S, Bouhout S, Bolduc S, Auger FA and Moulin VJ: Anticancer properties of chitosan on human melanoma are cell line dependent. Int J Biol Macromol 72: 370-379, 2015.

4. Weinstein D, Leininger J, Hamby C and Safai B: Diagnostic and prognostic biomarkers in melanoma. J Clin Aesthet Dermatol 7: 13-24, 2014.

5. Kim M, Miyamoto S, Yasui Y, Oyama T, Murakami A and Tanaka T: Zerumbone, a tropical ginger sesquiterpene, inhibits colon and lung carcinogenesis in mice. Int J Cancer 124: 264-271, 2009.

6. Yodkeeree S, Sung B, Limtrakul P and Aggarwal BB: Zerumbone enhances TRAIL-induced apoptosis through the induction of death receptors in human colon cancer cells: Evidence for an essential role of reactive oxygen species. Cancer Res 69: 6581-6589, 2009.

7. Sung B, Jhurani S, Ahn KS, Mastuo Y, Yi T, Guha S, Liu M and Aggarwal BB: Zerumbone down-regulates chemokine receptor CXCR4 expression leading to inhibition of CXCL12-induced invasion of breast and pancreatic tumor cells. Cancer Res 68: 8938-8944, 2008.

8. Prasannan R, Kalesh KA, Shanmugam MK, Nachiyappan A, Ramachandran L, Nguyen AH, Kumar AP, Lakshmanan M, Ahn KS and Sethi G: Key cell signaling pathways modulated by zerumbone: Role in the prevention and treatment of cancer. Biochem Pharmacol 84: 1268-1276, 2012.

9. Xian M, Ito K, Nakazato T, Shimizu T, Chen CK, Yamato K, Murakami A, Ohigashi H, Ikeda Y and Kizaki M: Zerumbone, a bioactive sesquiterpene, induces $\mathrm{G} 2 / \mathrm{M}$ cell cycle arrest and apoptosis in leukemia cells via a Fas- and mitochondria-mediated pathway. Cancer Sci 98: 118-126, 2007.

10. Murakami A, Takahashi D, Kinoshita T, Koshimizu K, Kim HW, Yoshihiro A, Nakamura Y, Jiwajinda S, Terao J and Ohigashi H: Zerumbone, a Southeast Asian ginger sesquiterpene, markedly suppresses free radical generation, pro-inflammatory protein production, and cancer cell proliferation accompanied by apoptosis: The alpha, beta-unsaturated carbonyl group is a prerequisite. Carcinogenesis 23: 795-802, 2002. 
11. Nakamura Y, Yoshida C, Murakami A, Ohigashi H, Osawa T and Uchida K: Zerumbone, a tropical ginger sesquiterpene, activates phase II drug metabolizing enzymes. FEBS Lett 572: 245-250, 2004.

12. Sakinah SA, Handayani ST and Hawariah LP: Zerumbone induced apoptosis in liver cancer cells via modulation of Bax/Bcl-2 ratio. Cancer Cell Int 7: 4, 2007.

13. Hosoya T, Arai MA, Koyano T, Kowithayakorn T and Ishibashi M: Naturally occurring small-molecule inhibitors of hedgehog/GLI-mediated transcription. Chembiochem 9: 1082-1092, 2008.

14. Sehrawat A, Arlotti JA, Murakami A and Singh SV: Zerumbone causes Bax and Bak-mediated apoptosis in human breast cancer cells and inhibits orthotopic xenograft growth in vivo. Breast Cancer Res Treat 136: 429-441, 2012.

15. Shan F, Shao Z, Jiang S and Cheng Z: Erlotinib induces the human non-small-cell lung cancer cells apoptosis via activating ROS-dependent JNK pathways. Cancer Med 5: 3166-3175, 2016.

16. Xu S, Zhong M, Zhang L, Wang Y, Zhou Z, Hao Y, Zhang W, Yang X, Wei A, Pei L and Yu Z: Overexpression of Tfam protects mitochondria against beta-amyloid-induced oxidative damage in SH-SY5Y cells. FEBS J 276: 3800-3809, 2009.

17. Xu S, Zhou Z, Zhang L, Yu Z, Zhang W, Wang Y, Wang X, Li M, Chen Y, Chen C, et al: Exposure to $1800 \mathrm{MHz}$ radiofrequency radiation induces oxidative damage to mitochondrial DNA in primary cultured neurons. Brain Res 1311: 189-196, 2010.

18. Xu SC, He MD, Zhong M, Zhang YW, Wang Y, Yang L, Yang J, Yu ZP and Zhou Z: Melatonin protects against Nickel-induced neurotoxicity in vitro by reducing oxidative stress and maintaining mitochondrial function. J Pineal Res 49: 86-94, 2010

19. Livak KJ and Schmittgen TD: Analysis of relative gene expression data using real-time quantitative PCR and the 2(-Delta Delta C(T)) method. Methods 25: 402-408, 2001

20. Xu C, Shen G, Yuan X, Kim JH, Gopalkrishnan A, Keum YS, Nair S and Kong AN: ERK and JNK signaling pathways are involved in the regulation of activator protein 1 and cell death elicited by three isothiocyanates in human prostate cancer PC-3 cells. Carcinogenesis 27: 437-445, 2006.

21. Jackson SJ and Singletary KW: Sulforaphane: A naturally occurring mammary carcinoma mitotic inhibitor, which disrupts tubulin polymerization. Carcinogenesis 25: 219-227, 2004.

22. Cummins DL, Cummins JM, Pantle H, Silverman MA, Leonard AL and Chanmugam A: Cutaneous malignant melanoma. Mayo Clin Proc 81: 500-507, 2006

23. Yang F, Yu Y, Lei Q, Zeng A, Li Y, Xie Y, Ye T and Wei Y: Lobaplatin arrests cell cycle progression, induces apoptosis and impairs migration and invasion in B16-F10 melanoma cell line in vitro. Biomed Pharmacother 69: 402-408, 2015.

24. Raj L, Ide T, Gurkar AU, Foley M, Schenone M, Li X, Tolliday NJ, Golub TR, Carr SA, Shamji AF et al: Selective killing of cancer cells by a small molecule targeting the stress response to ROS. Nature 475: 231-234, 2011.
25. Rajan I, Jayasree PR and Kumar PR: Zerumbone induces mitochondria-mediated apoptosis via increased calcium, generation of reactive oxygen species and upregulation of soluble histone H2AX in K562 chronic myelogenous leukemia cells. Tumour Biol 36: 8479-8489, 2015 .

26. Tanaka T, Shimizu M, Kohno H, Yoshitani S, Tsukio Y, Murakami A, Safitri R, Takahashi D, Yamamoto K, Koshimizu K, et al: Chemoprevention of azoxymethane-induced rat aberrant crypt foci by dietary zerumbone isolated from Zingiber zerumbet. Life Sci 69: 1935-1945, 2001

27. Hodi FS, O'Day SJ, McDermott DF, Weber RW, Sosman JA, Haanen JB, Gonzalez R, Robert C, Schadendorf D, Hassel JC, et al: Improved survival with ipilimumab in patients with metastatic melanoma. N Engl J Med 363: 711-723, 2010.

28. Gray-Schopfer V, Wellbrock C and Marais R: Melanoma biology and new targeted therapy. Nature 445: 851-857, 2007.

29. Friedl $P$ and Wolf K: Tumour-cell invasion and migration: Diversity and escape mechanisms. Nat Rev Cancer 3: 362-374, 2003.

30. Ju HK, Lee HW, Chung KS, Choi JH, Cho JG, Baek NI, Chung HG and Lee KT: Standardized flavonoid-rich fraction of Artemisia princeps Pampanini cv. Sajabal induces apoptosis via mitochondrial pathway in human cervical cancer HeLa cells. J Ethnopharmacol 141: 460-468, 2012.

31. Indran IR, Tufo G, Pervaiz S and Brenner C: Recent advances in apoptosis, mitochondria and drug resistance in cancer cells. Biochim Biophys Acta 1807: 735-745, 2011.

32. Xiao D, Powolny AA, Antosiewicz J, Hahm ER, Bommareddy A, Zeng Y, Desai D, Amin S, Herman-Antosiewicz A and Singh SV: Cellular responses to cancer chemopreventive agent $\mathrm{D}, \mathrm{L}-$ sulforaphane in human prostate cancer cells are initiated by mitochondrial reactive oxygen species. Pharm Res 26: 1729-1738, 2009.

33. Ghobrial IM, Witzig TE and Adjei AA: Targeting apoptosis pathways in cancer therapy. CA Cancer J Clin 55: 178-194, 2005.

34. Fulda S and Debatin KM: Extrinsic versus intrinsic apoptosis pathways in anticancer chemotherapy. Oncogene 25: 4798-4811, 2006.

35. Lemeshko VV: Potential-dependent membrane permeabilization and mitochondrial aggregation caused by anticancer polyarginine-KLA peptides. Arch Biochem Biophys 493: 213-220, 2010

36. Sarkar J, Singh N, Meena S and Sinha S: Staurosporine induces apoptosis in human papillomavirus positive oral cancer cells at G2/M phase by disrupting mitochondrial membrane potential and modulation of cell cytoskeleton. Oral Oncol 45: 974-979, 2009.

37. McLeod CJ, Pagel I and Sack MN: The mitochondrial biogenesis regulatory program in cardiac adaptation to ischemia-a putative target for therapeutic intervention. Trends Cardiovasc Med 15: $118-123,2005$. 